\title{
Investigation of the repair method alternatives for porous pet structures
}

DOI: $10.46932 /$ sfjdv2n1-021

Received in: November 1st, 2020

Accepted in: December 30th, 2020

\author{
Nihal Puhurcuoglu \\ Dokuz Eylul University - Mechanical Engineering \\ Master's Degree: Dokuz Eylul University -Department of Mechanical Engineering \\ Current Institution: TPI Composites \\ Address: Sasalı Mah. 1.Sokak No.70 35621 Cigli / IZMIR \\ E-mail: n.puhurcuoglu@tpicomposites.com \\ Utku Tiric \\ Dumlupinar University - Ceramic Engineering \\ Master's Degree: Dokuz Eylul University - Metallurgy and Materials Engineering \\ Current Institution : TPI Composites \\ Address: Sasal1 Mah. 1.Sokak No.70 35621 Cigli / IZMIR \\ E-mail: u.tiric@tpicomposites.com \\ Nur Karasahin \\ Middle East Technical University - Chemical Engineering \\ Master's Degree: Ege University - Chemical Engineering \\ Current Institution: TPI Composites \\ Address: Sasal1 Mah. 1.Sokak No.70 35621 Cigli / IZMIR \\ E-mail: NKarasahin@tpicomposites.com
}

\begin{abstract}
Wind turbine systems, which are one of the renewable energy sources, convert wind energy into electrical energy, cover the blade components those are produced as sandwich composite materials for the last half century. TPI Composite, a wind turbine blade manufacturer in the renewable energy sector, has an important position in the field.

In the sandwich composite structures, the core material providing the force transfer between the face sheets and plays an important role in increasing the bending stiffness of the sandwich structure. This nonstructural material component, which is thicker but lightweight, porous and low density, is used in the wind turbine blade subcomponents.

The main shear web (MSW), which is a subcomponent of the wind turbine composite blade and provides the mechanical strength between the two skins (suction side \& pressure side) of the blade, is a composite structure with a parabolic geometric distribution produced by vacuum infusion method. Due to the geometrical shape and placement of various shaped cores of the MSW, there might occur some gaps between the foam cores placed in the MSW during the production due to vacuum. In this study, compression and bending behaviors of the foam core were investigated. Specimens with dimensions of 50x50x30 mm were prepared vacuum infusion method of core structures whose top and bottom skins covered with glass-reinforced epoxy composite face sheets. Then, some specimens were filled with core powder and core strip respectively to represent the repair method. The test specimens were subjected to flatwise compression and three-point bending tests. The performances of different gap filling repair methods were compared, and the changing performance of the damaged core specimens were investigated against specimens without any defect. To evaluate the alternative repair methods that could be applied
\end{abstract}


during the production of MSW, gap filling repair alternatives, repair applicability limits and changing of the mechanical properties compared to virgin specimens were investigated for the sandwich structures with E-glass reinforced/epoxy face sheets and PET foam core.

Keywords: sandwich composite, porous PET, repair method, wind turbine blade.

\section{INTRODUCTION}

The cores are placed in the blade mold, there are some gaps between the cores. However, these gaps are not convenient for the blade manufacturing process and may reduce the mechanical performance of the blade. The purpose of the core is to maintain the distance between the laminates and to sustain shear deformations. It is possible to obtain various properties and desired performance by varying the core, the thickness of the laminated composites, and its materials [Heimbs et all., 2007].

The main shear web (MSW), which is a subcomponent of the wind turbine composite blade and provides the mechanical strength between the two skins (suction side \& pressure side) of the blade, is a composite structure with a parabolic geometric distribution produced by vacuum infusion method. Due to the geometrical shape and placement of various shaped cores of the MSW, there might occur some gaps between the foam cores placed in the MSW during the vacuum infusion manufacturing process. In this study, the mechanical properties of the foam core which affects the bending stiffness of the sandwich structure were investigated.

The increasing use of composites in the wind turbine blades manufacturing requires the development of proven repair methods that restore the integrity of the damaged structure, with minimum degradation in its functional capability and weight addition. Therefore, continued and expanded use of composites critically depends on the development of both structurally adequate and economically feasible, repair techniques [Raju et all., 2006]. The aim of this investigation is studying the mechanical performance of sandwich composites addition with core powder and core strip filled, separately, between the core materials compared to undamaged sandwich composite structures which is used in the manufacturing of the wind turbine blades. The undamaged (virgin) and repaired specimens were subjected to flexural (three-point bending) and flatwise compression tests and strength recoveries were measured to determine the efficacy of the repair technique employed.

\section{TEST PROCEDURE}

Sandwich composites are becoming more and more popular in structural design, mainly for their ability to substantially decrease weight while maintaining mechanical performance. Sandwich composite structures are made of two thin and rigid face sheets such as glass/carbon fiber reinforced composite 
material and a light, thick core material. Thin, high strength face sheets are separated by, and bonded to, lightweight core such as foam, honeycomb or balsa. The thicker the core, the stiffer the panel with minimal weight increase. They offer remarkable advantages such as high strength-to-weight ratio, high specific flexural rigidity, high fracture toughness and corrosion strength. Due to these advantages of the sandwich composite structures, these materials are widely used in diverse applications such as energy, automotive, aircraft and aerospace, marine and civil industries. In practically, these structures are usually subjected to various types of loadings such as tension, compression, bending and fatigue. Because of the difficulties in visually detecting damages under different types of loadings, understanding of the mechanical behavior of sandwich composite panels should be known to predict their strength [Henao et all., 2010].

The core in a sandwich composite material is a vital component which provides the minimum weight increasing with the considerable bending stiffness. One of the most driving reasons to use sandwich composites is that they provide mechanical properties to much lower weight than traditional monolithic materials. It is not only the sandwich principle itself that makes this possible. Sandwich composite materials also enable designers to engineer with extreme precision to their loading requirements. In other words, a sandwich solution will prevent over engineering, save weight and increase performance compared to many designs that use conventional materials such as steel. The combination of sandwich principle and the core material saves energy and enables faster and more effective solutions in many areas. For example, sandwich composite design is an absolute necessity to reach competitive cost per megawatt from the wind energy.

Repair techniques are regularly used in the composite materials to restore structural integrity and prolong their life without reducing the components functionality. The use of filling of the gaps between the consecutive cores for the performance assessment of sandwich composites has received considerable attention. Sandwich composites are easy to repair. One of the repair methods of the sandwich composites used in manufacturing of the wind turbine blades can be filling the gaps with the core powder or the core strip between the cores placed in the blade mold [Samali et all., 2019]. In this study, the mechanical performances of the different damaged and undamaged cores used in the sandwich structures are investigated.

The upper and lower faces carry compression and tension stresses in a sandwich structure under bending loads, respectively. Glass or carbon fiber which has a big impact on the final performance of the sandwich composite is the reinforcement material and fiber-reinforced plastic forms the face sheet. They can carry a very large portion of the loads applied. Epoxy resin or vinyl ester resin are often used as a matrix material in a composite structure and they hold the fibers together, protect them against the environmental damages and distribute the load applied to the fibers in an equal way [Salavati et all., 2014]. 
The core, which is another component of the sandwich composite, must fulfill the most complex demands. Strength in different directions and low density are not the only properties the core must have. There are often special demands for buckling, insulation, absorption of moisture, aging resistance, etc. The core can be made of a variety of materials such as foam, honeycomb or balsa. The properties of the core used in the manufacturing of the MSW is given in the Table 1. The function of the core in a sandwich composite material is to support the thin faces so that they do not buckle inwardly or outwardly, and to keep them in relative position to each other [Prabbhu et all., 2019]. To accomplish this, the core must have several important characteristics. It must be stiff enough to keep the distance between the faces to be constant. It must also be so rigid in shear that the faces do not slide over each other. The shear rigidity forces the faces to cooperate with each other. If the core is weak in shear, the faces will not cooperate, and the sandwich will lose its shear stiffness [Chen, 2002].

Table 1. Properties of the PET core [www.3ACCorematerials.com]

\begin{tabular}{l|l}
\hline Density & 100 \\
\hline $\begin{array}{l}\text { Compressive strength Perpendicular to } \\
\text { the Plane (MPa) }\end{array}$ & 1.5 \\
\hline $\begin{array}{l}\text { Compressive Modulus Perpendicular to } \\
\text { the Plane }(\mathrm{MPa})\end{array}$ & 100 \\
\hline $\begin{array}{l}\text { Tensile Strength Perpendicular to the } \\
\text { Plane (MPa) }\end{array}$ & 2.0 \\
\hline $\begin{array}{l}\text { Tensile Modulus Perpendicular to the } \\
\text { Plane (MPa) }\end{array}$ & 130 \\
\hline Shear Strength Lengthwise (MPa) & 1.05 \\
\hline Shear Strength Crosswise (MPa) & 0.8 \\
\hline Shear Modulus Lengthwise (MPa) & 33 \\
\hline Shear Modulus Crosswise (MPa) & 23 \\
\hline Shear Elongation at Break (\%) & 15 \\
\hline
\end{tabular}

Two material systems, as expected, have been used for the sandwich faces: E-glass/epoxy with the density of glass fiber oriented $\left[ \pm 45^{\circ}\right]$ in $1010 \mathrm{gr} / \mathrm{m}^{2}$. In terms of the core material, $100 \mathrm{~kg} / \mathrm{m}^{3}$ PET has been used. The sandwich composite panel together with these components is manufactured by vacuum infusion method.

Sandwich composite specimens with dimensions of 50x50x30 mm were prepared by the vacuum infusion method. Then, to represent the failure modes and the repair methods, the specimens were filled with core powder and core strip, respectively. The test specimens were subjected to flatwise tension, flatwise compression and three-point bending tests. The performances of different gap filling repair methods and whether the filling method is reduces strength of defective core specimens were investigated against specimens without any defect. In order to evaluate the alternative repair methods that could be applied during the manufacturing of MSW, gap filling repair alternatives, repair applicability limits were 
presented for the sandwich composite materials used in the wind turbine blades. The producing of the damaged sandwich specimens is shown in Figure 1.

Figure 1. The sandwich panel filled by the core powder (a) and the core strip (b)
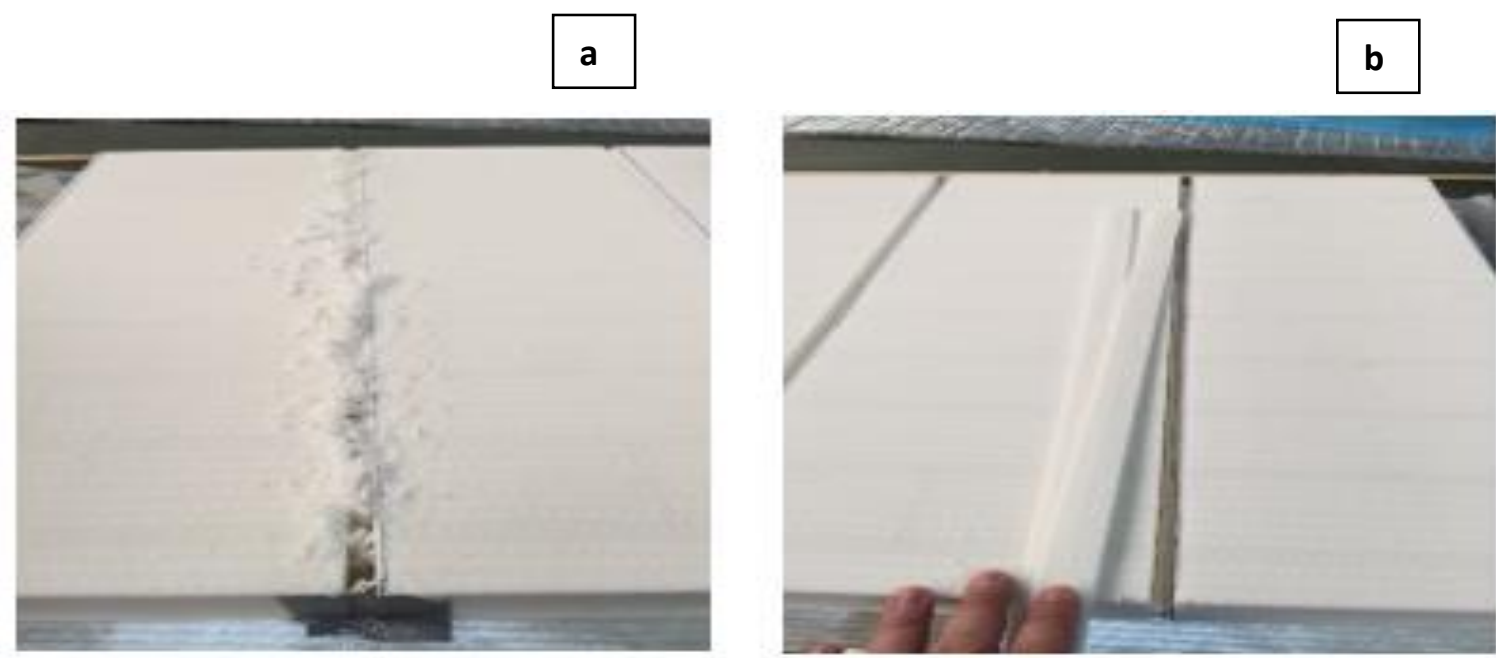

Figure 2 shows the preparation of the sandwich panel with vacuum infusion technique.

Figure 2. Sandwich panel with vacuum infusion technique.

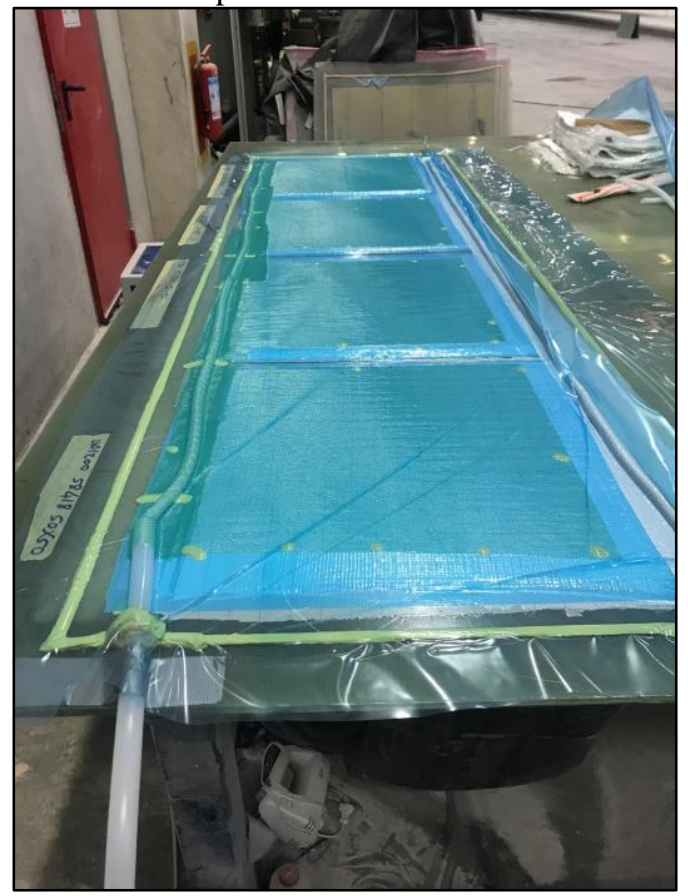

Flatwise compression tests were performed to determine the effects of the fillings on the mechanical properties of foam in the sandwich structure. This section discusses the procedures followed 
during the tests as well as the test results. In all the cases, five specimens were tested per every type of sandwich panel, all the results presented in this paper are obtained from valid tests.

Three-point bending tests were conducted according to ASTM C393/C 393M - 06 “'Standard Test Method for flexural properties of sandwich constructions". This test allows the determination of the facing bending strength. Flatwise compression and three-point bending tests specimen names: S: Strip, T: Powder and ST: Standard.

There are various possible failure modes in sandwich composites. One of them is the face-sheet bending. The flexural properties of the sandwich composite materials without crack and with gap filled at room temperature were determined by three-point bending test. The applied shear loading is carried principally by the core. The core is mainly subjected to shear loads and failure occurs when the maximum shear stress reaches the critical value (shear strength) of the core material. Compressive and tensile stresses occurred in the cross section of the specimen subjected to bending loading. The deformation characteristics of the materials were determined.

The behavior of the foam core sandwich structure was experimentally investigated for flatwise compression. The compressive strength along the normal axis of the core was determined to get ultimate strength and failure type of the structure. The specimens were tested to determine the compressive strength and the modulus of the sandwich composite material according to ASTM C365/ C365M-11 [ASTM Standard, 2011]. Figure 3 shows the compression force corresponding the stroke values.

Figure 3. Force-stroke curve of the specimens from flatwise compression test

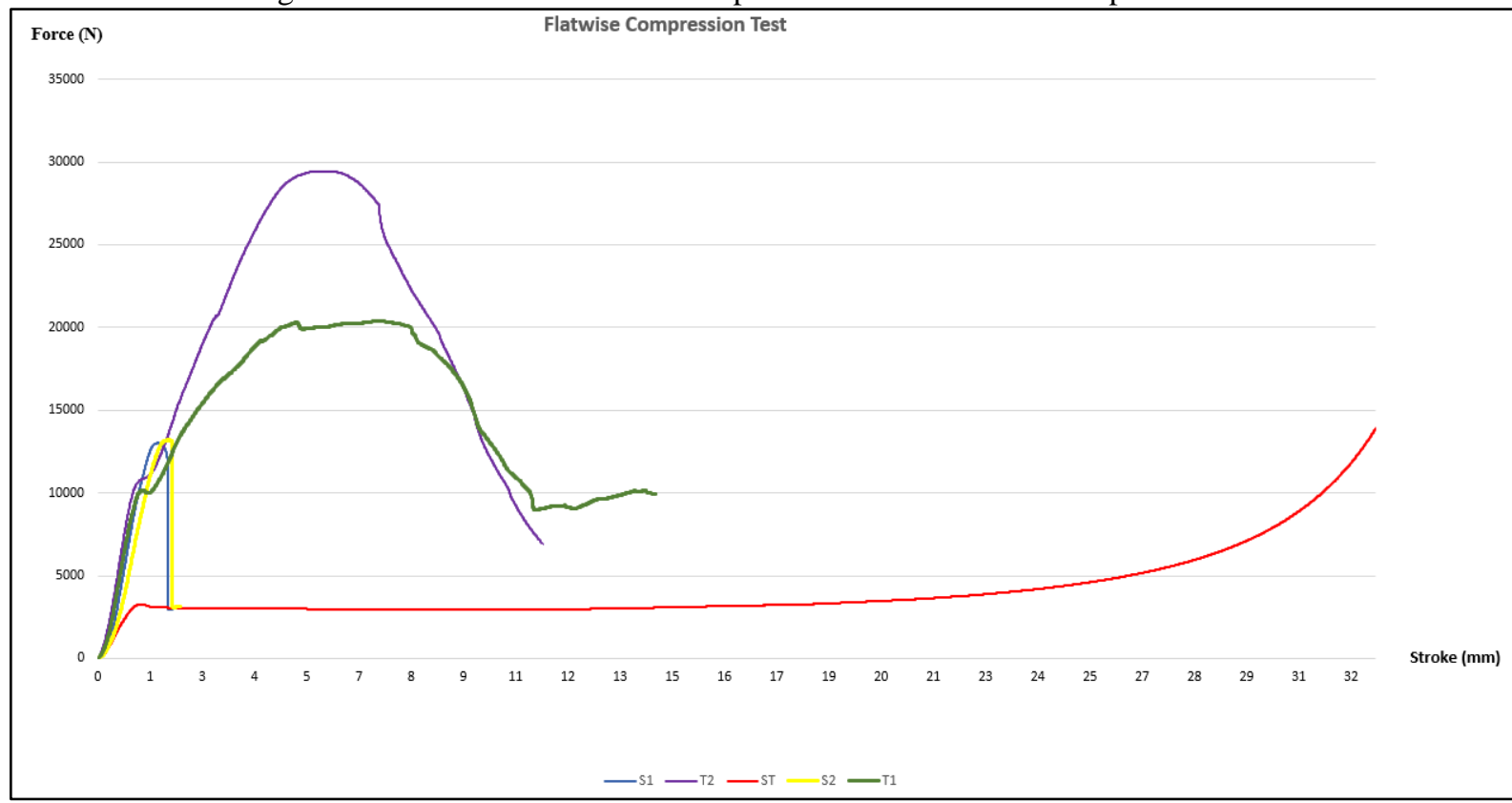


Figure 4. Force-stroke curve of the specimens from three-point bending test

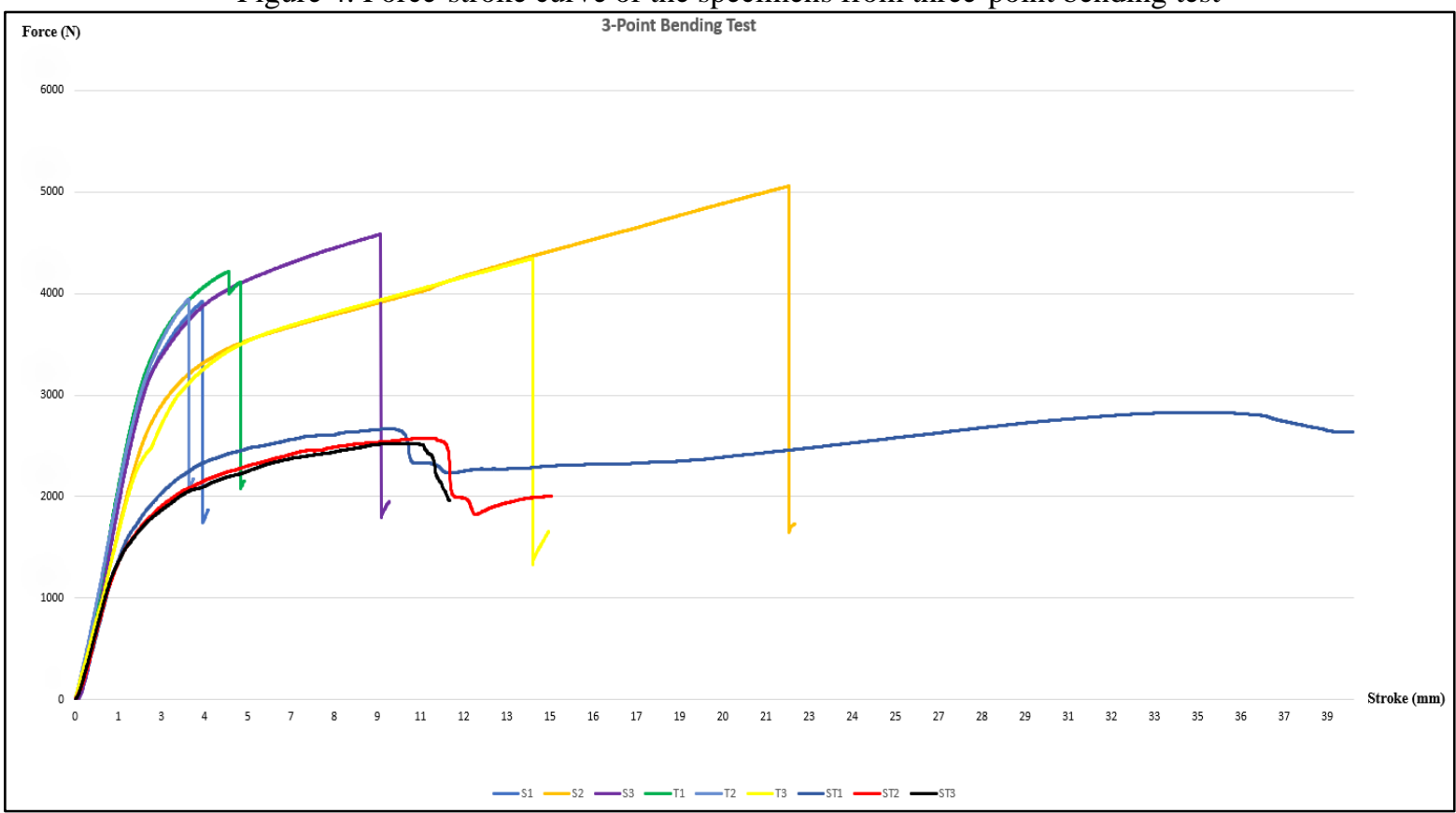

Table 2. The maximum and average forces obtained from the three-point bending test

\begin{tabular}{|c|c|c|c|}
\hline $\begin{array}{l}\text { Name of } \\
\text { Specimen }\end{array}$ & $\begin{array}{l}\text { Core } \\
\text { Filler }\end{array}$ & $\begin{array}{l}\text { Maximum } \\
\text { Force }(\mathrm{N})\end{array}$ & $\begin{array}{l}\text { Average } \\
\text { Force } \\
(\mathrm{N})\end{array}$ \\
\hline S1 & Strip & 3922 & \multirow{3}{*}{4521,6} \\
\hline S2 & Strip & 5058 & \\
\hline S3 & Strip & 4585 & \\
\hline T1 & Powder & 4216 & \multirow{3}{*}{4168,6} \\
\hline $\mathrm{T} 2$ & Powder & 3947 & \\
\hline $\mathrm{T} 3$ & Powder & 4343 & \\
\hline ST1 & No filler & 2672 & \multirow{3}{*}{2590,3} \\
\hline ST2 & No filler & 2575 & \\
\hline ST3 & No filler & 2524 & \\
\hline
\end{tabular}


Figure 5. The average forces obtained from the three-point bending test.

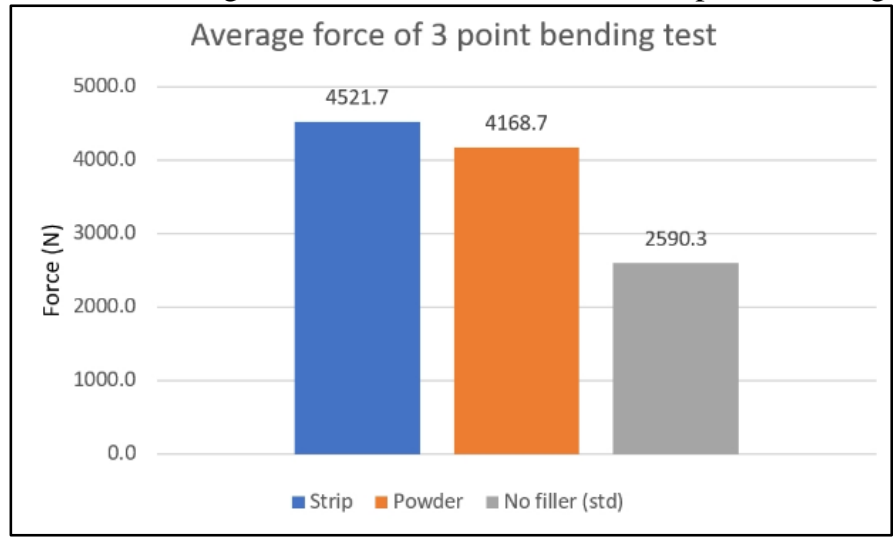

\section{CONCLUSION}

In the sandwich composites, the faces carry the tensile and compressive stresses, whereas the core's function is to support the thin face sheets. The core must have several important characteristics. One of them is to keep the distance between the faces constant to be stiff enough. It must also be rigid in shear that the faces do not slide over each other. The mechanical test procedure arises when the strength characterization of the sandwich composites is required. In this paper, the experimental methodology has been developed to study the mechanical behavior and flexural properties of sandwich composites which are used in wind turbine blade applications. In this study, the mechanical performance changing of the specimens subjected to the sandwich flatwise compression and three-point bending tests were carried out experimentally. The physical and mechanical properties of the sandwich structure of the rotor blade were investigated under the consideration of ASTM standards.

In this study, the repair method of the sandwich composites with foam core has been investigated experimentally in order to sandwich structures can meet the ultimate force. It is clear from the curves in the three-point bending that more appropriate repair method in terms of the maximum deflection corresponding the ultimate force the structure can carry is strip filling method. It has been experimentally obtained that one of the repair methods that can be applied to the core structures that increase the bending stiffness of sandwich structures by increasing the bending strength is strip filling method.

On the other hand, according to the flatwise compression test results the more appropriate repair method in terms of the ultimate force the structure can carry is powder filling. The sandwich material was able to carry more loading with powder filling method than the strip filling method.

Consequently, it is obviously seen that different type of repair method can be appropriate for the critical load bearing areas because each cross section meets different type of loading such as singular or distributed. 


\section{REFERENCES}

Raju M. Reddy C. R., Swamy M. R. and Giridhar G. (2006). Repair effectiveness studies on impact damaged sandwich composite constructions. Journal of Reinforced Plastics and Composites, 25:5-16. Henao A., Carrera M., Miravete A. and Castejon L. (2010). Mechanical performnce of through-thickness tufted sandwich structures. Composite Structures, 92:2052-2059.

Samali B., Nemati S., Sharafi P., Tahmoorian F. and Sanati F. (2019). Structural performance foam-filled building composite panels: a state of-the-art. Journal of Composite Science, 3(40):1-30.

Salavati S., Pershin L., Coyle T. W. and Mostaghimi J. (2014). Effect of porosity content of arc-sprayed alloy 625 skins on the flexural behavior of nickel foam core sandwich structures. Journal of Thermal Spray Technology, 24(1-2):215-221.

Prabbhu G., Katakam V., Sridharan V. S. and Idapalapati S. (2019). Uniaxial tensile failure of multi-core asymmetric sandwich composite structures with bonded repair. Composite Structures, 224:1-11.

Chen J. (2002). Predicting progressive delamination of stiffened fibre-composite panel and repaired sandwich panel by decohesion models. Journal of Thermoplastic Composite Materials, 15:429-442. www.3ACCorematerials.com

ASTM standard C365/C365M-11a. Standard test method for flatwise compressive properties of sandwich cores. Philadelphia, PA: ASTM International, 2011.

Heimbs S., Middendorf P., Kilchert S., Johnson A. F. and Majer M. (2007). Experimental and numerical analysis of composite folded sandwich core structures under compression. Appl. Compos. Mater, 14:363377. 